\title{
Influences of RE and RE-Ca modification on Microstructure and Mechanical Properties of Steel 35MnSiCrMoV
}

\author{
Zhenglian Tang ${ }^{1}$, Hongxia Zhang ${ }^{1}$ \\ ${ }^{1}$ School of Materials Science and Engineering, Hubei \\ University of Automotive Technology, Shiyan 442002, \\ China
}

\author{
Jian gang $\mathrm{Wu}^{2}$ \\ ${ }^{2}$ DongFeng Investment Casting CO., LTD, Shiyan 442714, \\ China
}

\begin{abstract}
Effects of different addition amounts of rare earth (RE) and Si-Ca on inclusions, the microstructure and mechanical properties of Steel $35 \mathrm{MnSiCrMoV}$ were investigated by accordingly using optical microscope, scanning electron microscopy with energy dispersive spectrometry, transmission electron microscope, tensile and impact testing machine. The results show that the addition amounts of RE and Si-Ca have significant impacts on the shape, size, distribution and quantity of inclusions, the microstructure and mechanical properties of steel $35 \mathrm{MnSiCrMoV}$. It can make the size of inclusions and the thickness of martensite reduce to nano scale and steel $35 \mathrm{MnSiCrMoV}$ obtain high strength, adequate ductility and high impact toughness at the same time through adding $0.3 \%$ (wt.\%) RE and $0.1 \% \mathrm{Si}-\mathrm{Ca}$ into the steel.
\end{abstract}

Keywords-mechanical properties; microstructure, rare earth; Si-Ca; 35MnSiCrMoV.

\section{INTRODUCTION}

It is known that RE elements have very important influences on the microstructure and mechanical properties of metals. The roles of RE metals can be summarized as purification, modification and alloying [1]. Because of their strong affinity with oxygen and sulphur, $\mathrm{RE}$ elements have been used both to deoxidize and desulfurize in steel $[2,3]$. RE Modification is a widely used method for improving the properties of iron steels, alloys and composites [4-10]. It was noticed that surplus RE does not enhance the properties of metals and alloys in any significant way [11]. Moreover, Studies [12] show that only RE modification is easy to cause RE to be oxidized and not easy to make it dissolved and dispersed; while, modifying by using $\mathrm{RE}$ and $\mathrm{Si}-\mathrm{Ca}$ other than $\mathrm{RE}$ have better effects on improving the morphology of non metallic inclusions, their distribution and even dispersion in the metallic matrix.

Based on our previous work, the effects of RE and Si$\mathrm{Ca}$ on inclusions, the microstructure and mechanical properties of a high performance low alloy Steel $35 \mathrm{MnSiCrMoV}$ developed by us were investigated in this study.

\section{EXPERIMENTAL PROCEDURE}

\section{A. Materials, casting and heat treating}

The chemical compositions(wt.\%, the same below) of the developed steel $35 \mathrm{MnSiCrMoV}$ are as follows: $\mathrm{C}, 0.3-$
0.4; Mn, 0.9-1.3; Si, 0.6-1.0; Cr, 0.5-0.9; RE, 0.04-0.1; Mo, 0.1-0.4; V, 0.06-0.15; $\mathrm{S}$ and $\mathrm{P},<0.03$; and balance, Fe. In order to investigate the exact effects of different adding amounts of $\mathrm{RE}$ and $\mathrm{Si}-\mathrm{Ca}$ on microstructure and mechanical properties of the developed steel $35 \mathrm{MnSiCrMoV}$, the contents of $\mathrm{C}, \mathrm{Mn}, \mathrm{Si}, \mathrm{Cr}$ Mo and $\mathrm{V}$ were limited to $0.32-0.35,1.05-1.15,0.75-0.85,0.65-0.75$, $0.15-0.20$ and $0.08-0.10$, respectively. The Si$\mathrm{Ca}(\mathrm{Ca}: 30.9 \%$, Si:56.8\%) and $\mathrm{RE}$ adding amounts and content of $\mathrm{Ce}$ in designed steel $35 \mathrm{MnSiCrMoV}$ for this research are given in Table 1.

TABLE 1. THE RE AND SI-CA ADDING AMOUNTS INTO STEELS STUDIED (WT. \%).

\begin{tabular}{ccccc}
\hline designation & $\begin{array}{c}\text { RE adding } \\
\text { fraction }\end{array}$ & $\mathrm{Ce}$ & $\mathrm{S}$ & $\begin{array}{c}\text { Si-Ca adding } \\
\text { fraction }\end{array}$ \\
\hline 1A & - & 0.005 & 0.018 & - \\
1B & 0.1 & 0.017 & 0.016 & - \\
1C & 0.2 & 0.024 & 0.014 & - \\
1D & 0.3 & 0.038 & 0.012 & - \\
1E & 0.4 & 0.053 & 0.016 & - \\
2A & 0.3 & 0.041 & 0.010 & 0.05 \\
2B & 0.3 & 0.044 & 0.013 & 0.10 \\
2C & 0.3 & 0.046 & 0.012 & 0.15 \\
\hline
\end{tabular}

The steel was smelted in a $150 \mathrm{~kg}$ medium frequency induction furnace. The chemical compositions of all heats were detected by QS7500 direct reading spectrometer. Graphite, ferromanganese, ferrosilicon, ferrochromium, ferromolybdenum and ferrovanadium were added to the melts to adjust elements contents after complete melting of base material. RE-Si-Fe alloy (RE: $35 \%$, Ce/RE:73\%, $\mathrm{Si}: \leq 36 \%, \mathrm{Mn}: 1.8 \%$, Ca: $3.7 \%$, Ti: $0.3 \%$, the rest: $\mathrm{Fe}$ ) and $\mathrm{Si}-\mathrm{Ca}$ alloy were introduced into the ladle during tapping of deoxidized steel from the furnace.

All heats were poured into ceramic shell moulds to cast into keel blocks via investment casting. After casting, blank samples were cut down along the dashed-line shown in Fig. 1. Subsequently, they were normalized after $2 \mathrm{~h}$ at $920^{\circ} \mathrm{C}$ and then austenitized for $2 \mathrm{~h}$ at $920^{\circ} \mathrm{C}$ and water quenched, followed by tempering at $560{ }^{\circ} \mathrm{C}$ for $2 \mathrm{~h}$. All samples were heat treated in an open electric furnace.

\section{B. Microstructural characterization}

Metallographic samples were cut down from blank samples, prepared using standard polishing techniques, etched with $4 \%$ Nital and studied under a XJP-100 optical microscope and OMNIMET image analysis system. 
Microstructural and fractographic examinations of specimens were carried out in a scanning electron microscope (SEM, JSM-6510LV, $30 \mathrm{kV}$ ) equipped with an energy dispersive spectroscopy (EDS) analyzer to allow a better understanding of the microstructures and micro mechanisms of fracture in different steel $35 \mathrm{MnSiCrMoV}$.

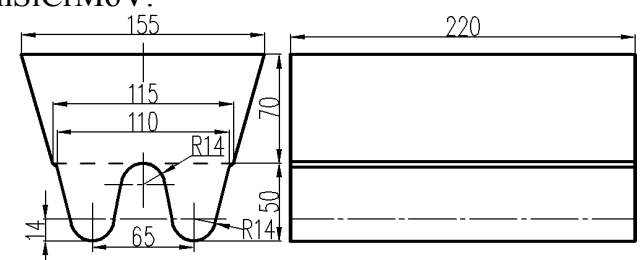

Fig.1. Keel block

For transmission electron microscope (TEM) analysis, slices of about $400 \mu \mathrm{m}$ in thickness were cut using an electro-discharge machine (EDM). These samples were subsequently ground to a thickness of $100 \mu \mathrm{m}$. Discs of about $3 \mathrm{~mm}$ in diameter were punched from the thinned wafers and TEM foils were prepared by electropolishing these discs at $-20^{\circ} \mathrm{C}$ in a MTP-1A twin-jet polisher using the electrolyte consisted of 5\% perchloric acid and 95\% ethanol solution. The specimens were examined in a JEM 2100F microscope (JEOL) at an operating voltage of 120 $\mathrm{kV}$.

\section{Mechanical properties test}

Dogbone-shaped specimens with a gage diameter of $10 \mathrm{~mm}$ and a gage length of $60 \mathrm{~mm}$ were used to evaluate tensile mechanical properties such as UTS and elongation of steel $35 \mathrm{MnSiCrMoV}$ by means of a MTS 4305 testing machine using a strain rate of $5.6 \times 10^{-4} \mathrm{~s}^{-1}$ at ambient temperature of $25^{\circ} \mathrm{C}$.

Impact tests were conducted by using one-fourth size Charpy specimens with geometry of $2.5 \times 10 \times 55$ (width $\times$ thickness $\times$ length, $\mathrm{mm}^{3}$ ) and a standard $2 \mathrm{~mm}$ deep Vnotch $(1 / 4 \mathrm{CV})$ in the middle of the specimens on a SANS J13-30\15 impact testing machine at room temperature.

\section{RESULTS AND DISCUSSION}

\section{A. Microstructures of steel 35MnSiCrMoV}

The as-cast microstructures of steel $35 \mathrm{MnSiCrMoV}$ are shown in Fig. 2, where 1A, 1B and 1C show coarsegrained, while $1 \mathrm{D}$ and $1 \mathrm{E}$ exhibit greatly refined grains. The reason is that the RE adding amounts in $1 \mathrm{~A}, 1 \mathrm{~B}$ and $1 \mathrm{C}$ was lower than that in $1 \mathrm{D}$ and $1 \mathrm{E}$, which is not sufficient to refine grains. At the same time, it can be seen that the grain size of $1 \mathrm{E}$ was larger than that of $1 \mathrm{D}$ because the excessive RE made grains coarsened again [13].

Fig. 3 display that inclusions and microstructures of quenched and tempered (Q\&T) steels became increasingly fine with the increase of RE addition amount from 0 to $0.3 \%$. The size of inclusions and thickness of martensite respectively reduce to below $50 \mathrm{~nm}$ and $200 \mathrm{~nm}$ when adding $0.3 \% \mathrm{RE}$.

\section{B. The inclusions in steel $35 \mathrm{MnSiCrMoV}$}

Fig. 4 shows the unetched metallograph of inclusions in as-cast steels 1A, 1B, 1C, 1D and 1E. All inclusions are globular and hardly cut matrix. The volume fraction of inclusions decreased gradually with increasing $\mathrm{RE}$ addition amounts

The inclusions in 1A were larger than those in other steels. Inclusions in 1D were fine and the size of them was more uniform. Inclusions in $1 \mathrm{E}$ were larger than hose in $1 \mathrm{D}$.

In non-metallic elements, sulfide is an important factor bringing inclusions in steels. After adding RE, the composition, shape and distribution of inclusions in steels can be improved. It had been indicated that $\mathrm{RE} / \mathrm{S}$ ratio increases and the volume fraction of inclusions decreases with increasing RE content [14]. The results obtained in this study are coincident with the above. As is known, the $\mathrm{RE} / \mathrm{S}$ ratio in $1 \mathrm{D}$ was greater than $3, \mathrm{MnS}$ inclusions were replaced by near-spherical, fine, dispersive RE inclusions, and thus the micro-cutting effect to the matrix was reduced.

2B and 2C. There was a high quantity of inclusions and the size of inclusions was big in steel 1D without adding Si-Ca (Fig. 5 (a)). Large inclusions gradually turned into near-spherical or spherical dispersive fine inclusions through $\mathrm{RE}-\mathrm{Ca}$ modifying after adding $\mathrm{Si}-\mathrm{Ca}$ into the steel (Fig. 5 (b), (c)). Also, the quantity of inclusions decreased gradually with increasing $\mathrm{Si}-\mathrm{Ca}$ addition amounts. When the Si-Ca addition amount was up to $0.10 \%$, only a very small quantity of inclusions remained in steel $2 \mathrm{~B}$. This demonstrates the role of $\mathrm{Si}-\mathrm{Ca}$ on purifying steel and reducing the inclusion. While adding $\mathrm{Si}-\mathrm{Ca}$ up to $0.15 \%$, inclusions increased and largened again in steel $2 \mathrm{C}$, which indicates that overmuch $\mathrm{Si}-\mathrm{Ca}$ leads to inclusions such as $\mathrm{CaO}$ and/or $\mathrm{CaS}[15,16]$.

Fig. 6 presents the EDS and quantitative analysises of inclusions in Q\&T steel $1 \mathrm{D}$ and 2B. It shows that inclusions in steel $35 \mathrm{MnSiCrMoV}$ without adding $\mathrm{Si}-\mathrm{Ca}$ were mainly composed of $\mathrm{MnS}$ and $\mathrm{Al}_{2} \mathrm{O}_{3}$ (Fig. 6 (a)). After adding $0.1 \%$ Si-Ca into steel $35 \mathrm{MnSiCrMoV}, \mathrm{Mn}$ in inclusions was replaced by RE and $\mathrm{Ca}$ (Fig. 6 (b)). So, inclusions in steel $2 \mathrm{~B}$ became mainly consisting of the RE-Ca-O-S type composite rare earth oxysulfide. This indicates that RE-Ca modification can make the oxide and sulfide such as $\mathrm{Al}_{2} \mathrm{O}_{3}$ and $\mathrm{MnS}$ transform into easy floating and removing composite rare earth oxysulfide, so as to realize controlling the shape, size, distribution and quantity of inclusions in steel $35 \mathrm{MnSiCrMoV}$.

\section{Mechanical properties of steel 35MnSiCrMoV}

Mechanical properties of Q\&T steel $35 \mathrm{MnSiCrMoV}$ are shown in Table 2 . It manifests that $1 / 4 \mathrm{CV}$ energy and product of UTS and elongation (comprehensive mechanical properties) of steel $35 \mathrm{MnSiCrMoV}$ improved with increasing $\mathrm{RE}$ and $\mathrm{Si}-\mathrm{Ca}$ addition amounts if only the adding amounts of $\mathrm{RE}$ and $\mathrm{Si}-\mathrm{Ca}$ were respectively no more than $0.3 \%$ and $0.10 \%$, and content of Ce was, not exceeding $0.05 \%$. The result indicates that $0.3 \% \mathrm{RE}$, $0.10 \% \mathrm{Si}-\mathrm{Ca}, 0.03-0.05 \% \mathrm{Ce}$ were more helpful to 
enhance comprehensive mechanical properties of steel $35 \mathrm{MnSiCrMoV}$ than other $\mathrm{RE}$ and $\mathrm{Si}-\mathrm{Ca}$ addition amounts and content of $\mathrm{Ce}$. These were closely related to and consistent with microstructures of steel $35 \mathrm{MnSiCrMoV}$ and the shape, size, distribution and quantity of inclusions in steel $35 \mathrm{MnSiCrMoV}$ which were respectively analyzed in 3.1 and 3.2

Fig. 7 exhibits the fractographic morphologies of the tensile and impact tested specimens of Q\&T steel $35 \mathrm{MnSiCrMoV}$. Clearly, the fracture surfaces of steel $35 \mathrm{MnSiCrMoV} 1 \mathrm{~A}$ specimen had small area reduction (a1, a3), and mainly consisted of quasi-cleavage facets with some relatively large cleavage steps, and many large secondary microcracks (a2, a4), indicating the increased brittleness. With the adding of RE into steel $35 \mathrm{MnSiCrMoV}$, the area reduction of steel 1D specimen increased (b1, b3), their fractographs were full of dimples (b2, b4), which imply much better ductility and toughness The fracture surfaces of steel $35 \mathrm{MnSiCrMoV} 2 \mathrm{~B}$ specimen showed the largest area reduction (c1, c3), fewest secondary small-size microcracks and many uniformly distributed deep dimples (c2, c4). These fractographies were identified with the mechanical properties of different steels.

TABLE 2. MECHANICAL PROPERTIES OF Q\&T STEELS

\begin{tabular}{cccccc}
\hline designation & $\begin{array}{c}\text { UTS } \\
(\mathrm{MPa})\end{array}$ & $\begin{array}{c}\text { Yield } \\
\text { strength } \\
(\mathrm{MPa})\end{array}$ & $\begin{array}{c}\text { Elongation } \\
(\%)\end{array}$ & $\begin{array}{c}\text { Product of } \\
\text { UTS and } \\
\text { elongation } \\
(\mathrm{MPa} \%)\end{array}$ & $\begin{array}{c}1 / 4 \mathrm{CV} \\
\text { energy } \\
(\mathrm{J})\end{array}$ \\
\hline 1A & 1025 & 890 & 7.9 & 8098 & 4.0 \\
1B & 1068 & 938 & 8.8 & 9398 & 4.5 \\
1C & 1110 & 961 & 10.1 & 11211 & 4.9 \\
1D & 1123 & 985 & 11.0 & 12353 & 6.0 \\
1E & 1137 & 970 & 9.5 & 10802 & 5.1 \\
2A & 1291 & 1220 & 10.4 & 13426 & 7.9 \\
2B & 1306 & 1245 & 12.7 & 16586 & 8.3 \\
2C & 1294 & 1210 & 11.3 & 14622 & 7.7 \\
\hline
\end{tabular}

\section{CONCLUSION}

(1) With increasing the RE adding amount into designed steel $35 \mathrm{MnSiCrMoV}$ from 0 to $0.3 \%$, the quantity of inclusions decrease gradually; the dispersion of inclusions and microstructure improve gradually. The size of inclusions and thickness of martensite respectively can reduce to below $50 \mathrm{~nm}$ and $200 \mathrm{~nm}$ at the addition amount of rare earth being $0.3 \%$. While, the size of inclusions increases again thereafter with the addition amount up to $0.4 \%$.

(2) RE-Ca compound modification can make the quantity of inclusions in

designed steel $35 \mathrm{MnSiCrMoV}$ reduce gradually and large inclusions mainly composed of $\mathrm{MnS}$ gradually turn into near-spherical or spherical dispersive fine inclusions mainly consisting of the RE-Ca-O-S type composite rare earth oxysulfide with the $\mathrm{Si}-\mathrm{Ca}$ addition amount from 0 to $0.10 \%$. But the quantity of inclusions would increase again when $\mathrm{Si}-\mathrm{Ca}$ is added up to $0.15 \%$.
(3) Through RE-Ca modifying by adding $0.3 \% \mathrm{RE}$ and $0.10 \% \mathrm{Si}-\mathrm{Ca}$ into designed steel $35 \mathrm{MnSiCrMoV}$ to contain $0.03-0.05 \% \mathrm{Ce}$, the UTS, yield strength, elongation and $1 / 4 \mathrm{CV}$ energy of it can respectively reach to $1306 \mathrm{MPa}, 1245 \mathrm{MPa}, 12.7 \%$ and $8.3 \mathrm{~J}$.

\section{ACKNOWLEDGEMENTS}

This research was financially supported by Dongfeng Investment Casting Co., Ltd. (Shiyan, China) attached to Dongfeng Motor Corporation (Wuhan, China) and by the Doctoral Research Foundation of Hubei University of Automotive Technology.

\section{REFERENCES}

[1] L.M. Wang, Q. Lin, L.J. Yue, L. Liu, F. Guo, F.M. Wang, Study of application of rare earth elements in advanced low alloy steels. J. Alloy Comp., 451(1-2), pp.534-537, 2008.

[2] A. Vahed, D.A.R. Kay, Metall, Thermodynamics of rare earths in steelmaking .Trans. B 7B, pp.375-383, 1976.

[3] W.G. Wilson, D.A.R. Kay, A. Vahed, The use of thermodynamics and phase equilibria to predict the behavior of the rare earth elements in steel. J. Met., 26(5), pp.14-23, 1974.

[4] P.E. Waudby, Rare earth additions to steel. Int. Met. Rev, 23 (2), pp.74-98, 1978.

[5] H. Fu, Q. Xiao, Y. Li, A study of the microstructures and properties of Fe-V-W-Mo alloy modified by rare earth. Mat. Sci. Eng. A, 395(1-2), pp.281-287, 2005.

[6] M. Boccalini, A.V.O. Correa, H. Goldenstein, Rare earth metal induced modification of gamma-M2C, gamma-M6C, and gammaMC eutectics in as cast M2 high speed steel. Mat Sci Tech., 15, pp.621-626, 1999.

[7] X. Chen, Y. Li, Fracture toughness improvement of austempered high silicon steel by titanium, vanadium and rare earth elements modification. Mat. Sci. Eng. A, 444, pp.298-305, 2007.

[8] Q.F. Guan, J.R. Fang, Q.C. Jiang, S.Q. Wang, Effect of rare earth composite modification on microstructure and properties of a new cast hot-work die steel. J. Rare Earth, 21, pp.368-371, 2003.

[9] F. Han, C. Wang, Modifying high Cr-Mn cast iron with boron and rare earth-Si alloy. Mat Sci Tech., 5, pp.918-924, 1989.

[10] J. Lan, J.J. He, W.J. Ding, Study on heterogeneous nuclei in cast H13 steel modified by rare earth. J. Rare Earth, 19, pp.280-283, 2001.

[11] J. Kasińska, M. Gajewski, Wide-Ranging Influence of Mischmetal on Properties of GP240GH Cast Steel. Arch. Foundry Eng., 12(4), pp.85-94, 2012.

[12] X.L. Dun, K.P. Liu, H.S. Liu, J.P. Lai, X.H. Fu, J. Zhou, Effect of multicomponent modifier on microstructure and mechanical properties of high Ni-Cr-Mo cast iron. Mat Sci Tech., 27(12), pp.1840-1845, 2011.

[13] M.Q. Li, C. Ma, D.M. Liu, Influence of light rare earth on toughness of welded seam of LAHS steel. J. Rare Earth , 21(1), pp.77-80, 2003.

[14] W.G. Wilson, D.A.R. Kay, A. Vaoed, Use of Thermodynamics and Phase Equilibria to Predict the Behavior of the Rare Earth Elements in Steel. J Met., 26 (5), pp.14-23, 1974.

[15] H. Osamu, E. Toshihiko, K. Goro, N. Masao, M. Saburo, Mechanism of Sulfide Shape Control in Continuously Cast HSLA Steel Slabs Treated With Ca and/or RE. Tetsu to Hagane, 66 (3), pp.354-362, 1980.

[16] Blazenko Korousic, Fundamental Thermodynamic Aspect of the $\mathrm{CaO}-\mathrm{Al}_{2} \mathrm{O}_{3}-\mathrm{SiO}_{2}$ System. Steel Res., 62(7), pp.285-288, 1991. 

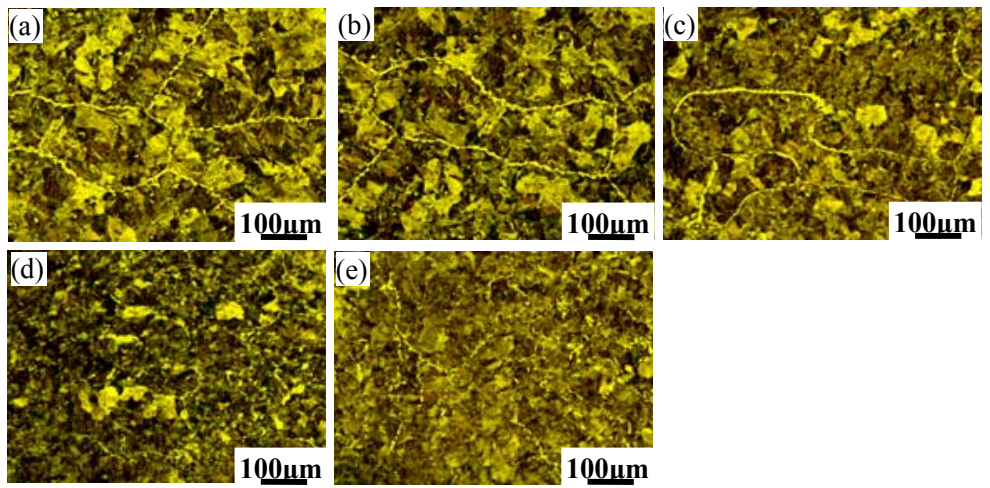

Fig.2. The as-cast microstructures of steels $1 \mathrm{~A}-1 \mathrm{E}$ (a-e)
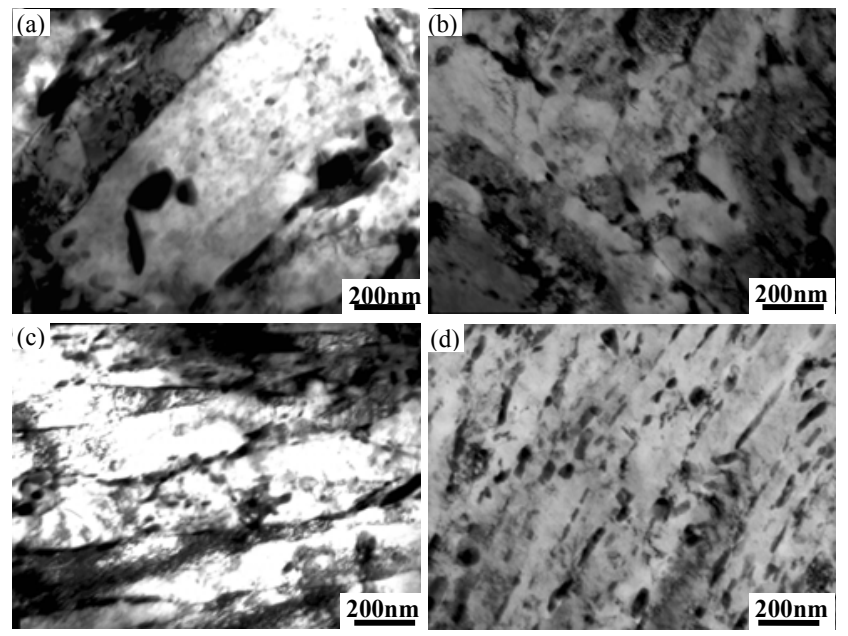

Fig.3. TEM micrographs of Q\&T steels 1A (a), 1B (b), 1C (c) and 1D (d)

(a)

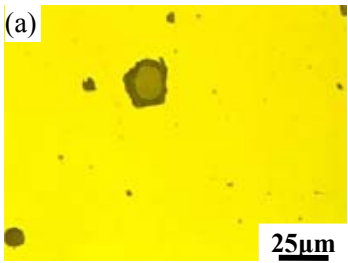

(d) (b)

$25 \mu \mathrm{m}$

\begin{abstract}
(e)
\end{abstract}
e) (c)
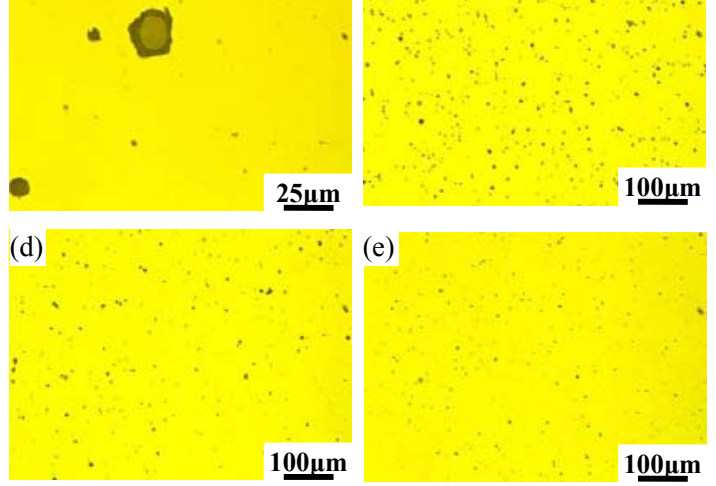

$100 \mu \underline{m}$

$100 \mu \mathrm{m}$

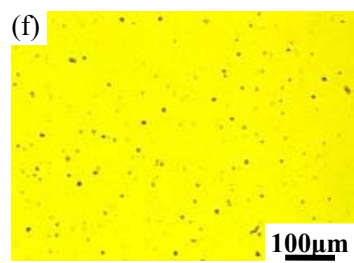

Fig.4. Inclusions in as-cast steels 1A ((a) high magnification; (b), low magnification), 1B (c), 1C (d), 1D (e) and 1E (f). 

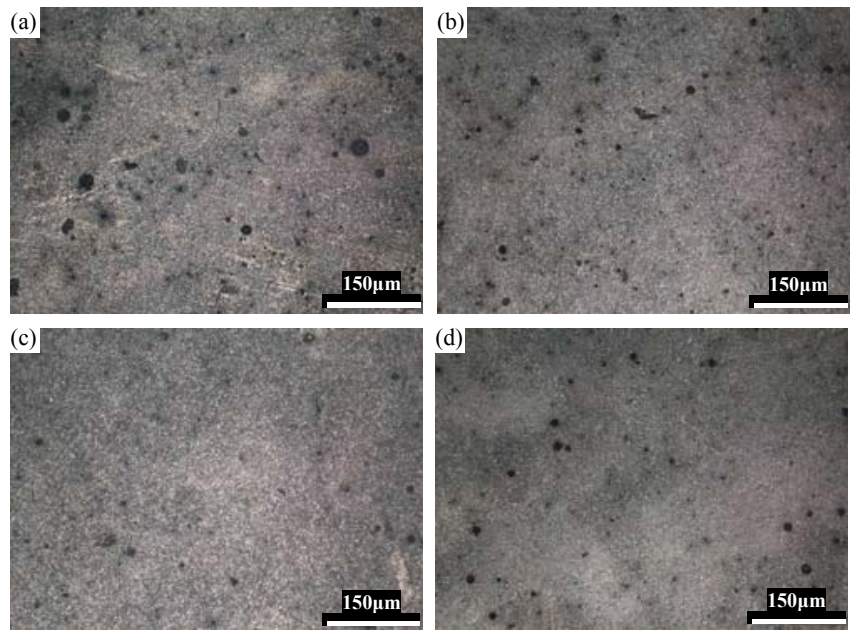

Fig.5. Inclusions in Q\&T steels 1D (a), 2A (b), 2B (c) and 2C (d).
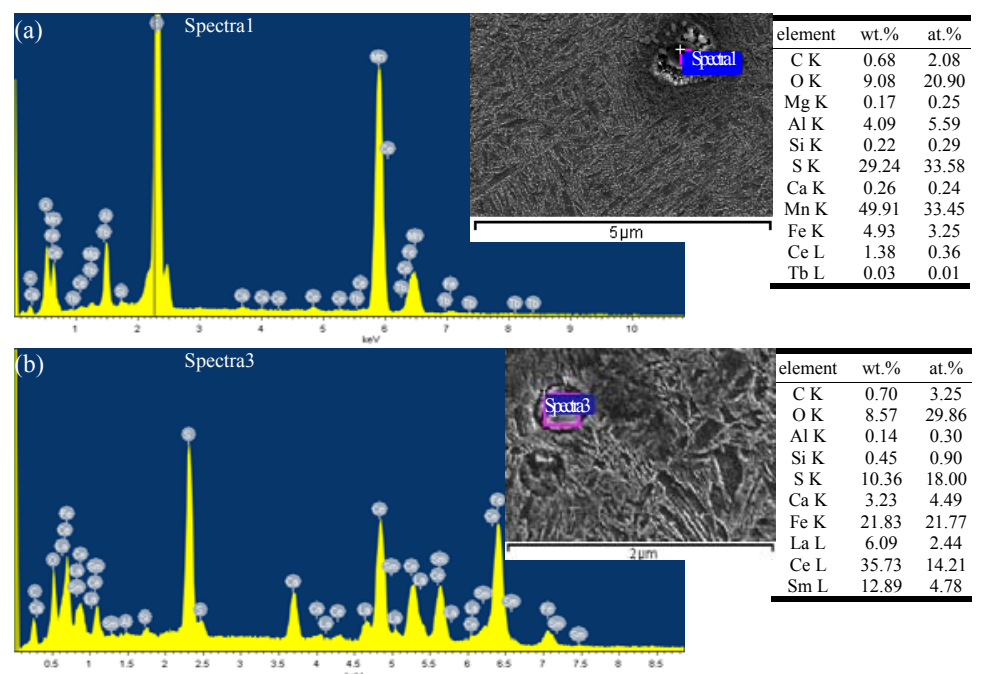

Fig.6. EDS and quantitative analysises of inclusions in Q\&T steels 1 (a) and 2B (b). 


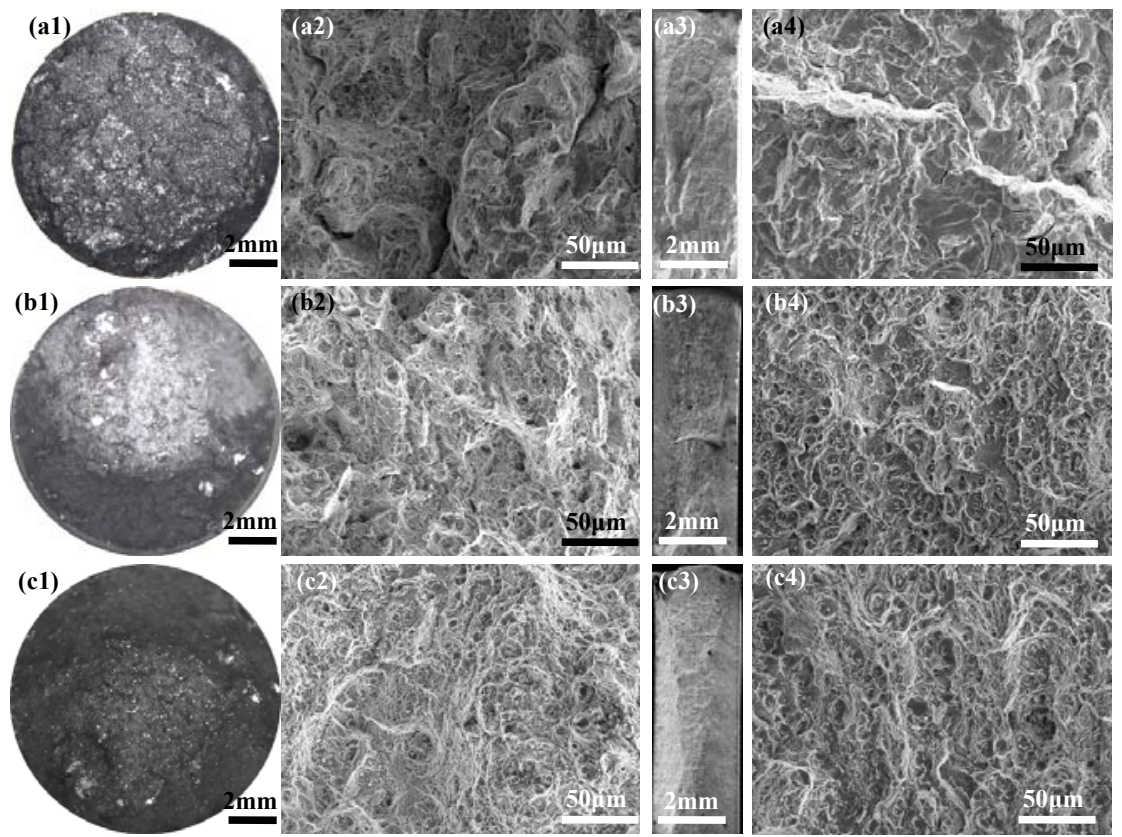

Fig.7. Fractographic morphologies of the tensile and impact tested specimens of Q\&T steels 1A (a1 to a4), 1D (b1 to b4) and 2B (c1 to c4). 